\title{
CNC Turning Parameter Optimization for Surface Roughness of Aluminium-2014 Alloy Using Taguchi Methodology
}

\author{
Abhishek Aswal, Aditya Jha, Anshul Tiwari, Yashwant Kumar Modi* \\ Department of Mechanical Engineering, Jaypee University of Engineering and Technology, Guna 473226, MP, India
}

Corresponding Author Email: yashwant.modi@juet.ac.in

https://doi.org/10.18280/jesa.520408

Received: 19 April 2019

Accepted: 16 July 2019

\section{Keywords:}

analysis of variance (ANOVA), computer numerical control (CNC) turning, optimization, Taguchi method, surface roughness, signal-to-noise ratio (SNR)

\begin{abstract}
The optimization of machining parameters is critical to the quality of machined products and the production rate. This paper aims to optimize the surface roughness of aluminium-2014 alloy by adjusting the machining parameters of computer numerical control (CNC) turning, including, cutting speed, depth of cut and feed rate. According to L9 orthogonal array, a total of nine experiments were conducted according to Taguchi method with different parameter settings. The surface roughness of the machined products was measured by a roughness tester, and evaluated by signal-to-noise ratio (SNR). The analysis of variance (ANOVA) was conducted to find the optimal parameter settings for surface roughness. The results show that the cutting speed is the most influential parameter $(67.28 \%)$ on surface roughness, followed by feed rate $(32.28 \%)$ and depth of cut $(0.33 \%)$ for surface roughness. Hence, the surface roughness can be optimized by minimizing the feed rate and depth of cut.
\end{abstract}

\section{INTRODUCTION}

Surface roughness $\left(R_{a}\right)$ is very important quality characteristic of a part in an engineering organisation. It has substantial influence on various properties of the manufactured part viz. wear and corrosion resistance, fatigue strength, lubricant holding and distribution capability, heat generation and transmission etc. This paper demonstrates the application of the Taguchi design of experiment approach for evaluating optimum turning parameters responsible for rough surface of 2014 aluminium alloy in absence of cutting fluid. Taguchi's design of experiment (DOE) is a proven and systematic statistical method to design robust products and processes. The conventional design (factorial design) requires repeated experiments, whereas Taguchi approach needs relatively lesser number of experiments to arrive at optimum combination of parameters by using orthogonal array. The Taguchi method is an alternative method to review loss due to poor quality. It's also known as robust design, and seeks to minimize the sensitivity to noise for any product and/or process. The conventional loss function states that products may be accepted if they are within statistical tolerance limits. Taguchi's loss function states that there is a loss unless the product exactly adheres to the target. Hence, it is required to identify the best possible set of turning parameters which results in optimum response by performing various experiments. To achieve a good surface roughness, a balanced setting of turning parameters is needed prior to actual turning operation.

The aim of this work is to evaluate various turning parameters for optimum roughness in aluminium 2014 alloy. Optimize the process parameters through only a few experiments, Taguchi's $\mathrm{L}_{9}$ orthogonal array for three factors namely, cutting speed $(V)$, depth of cut $(d)$ and feed rate $(f)$ with three levels each is selected. Average surface roughness $\left(R_{a}\right)$ was used among various measures available to evaluate the surface roughness.

\section{LITERATURE REVIEW}

Masounave et al. [1] optimized process parameters viz. cutting speed, feed rate, depth of cut, tool nose radius for minimizing the surface roughness and found the shorter tool length as most significant factor. Ghani and Choudhury [2] described the procedures to obtain surface roughness for various turning parameters. Gopalsamy and Mondal [3] applied Taguchi method to obtain optimum machining parameters in end milling of hardened steel. They used four parameters: cutting speed, feed, depth of cut and width of cut to optimize the tool life and surface finish using $\mathrm{L}_{18}$ orthogonal array. They found the cutting speed most dominant factor for surface finish and tool life. Sarýkaya [4] optimized the parameter such as cutting speed, feed rate, cooling condition and obtained optimum surface roughness and tool life for face milling of stainless steel. Surace et al. [5] took pressure, temperature, $\mathrm{SiC}$ fraction to optimize relative density and energy efficiency done on aluminium foam as workpiece material. Dahbi et al. [6] optimized surface roughness using cutting speed, feed rate, depth of cut, nose radius as input factors and found feed rate and nose radius as the most significant factor. Yang and Tarng (1998) investigated the contribution of cutting parameters namely cutting speed, feed rate and depth of cut in turning of S45C steel using Taguchi method. They employed orthogonal array, signal-to-noise ratio and ANOVA for finding out the contribution of individual parameters and the most influential parameter [7]. Pang et al. (2014) optimized depth of cut, cutting speed and feed rate in CNC end milling of halloysite nanotube with aluminium reinforced epoxy matrix (HNT/Al/Ep) hybrid composite for surface roughness and cutting force using Taguchi method [8]. Nalbant et al. [9] 
used Taguchi method to find the optimal cutting parameters namely, insert radius, feed rate, and depth of cut for surface roughness in turning operation of AISI 1030 steel bars using TiN coated tool. Hasçalık and Çaydaş [10] obtained the effect and optimization of cutting speeds, feed rates, and depths of cut on surface roughness and tool life in a turning of commercial Ti-6Al-4V alloy using CNMG 120408-883 insert cutting tools via Taguchi method. The orthogonal array, signal-to-noise $(\mathrm{S} / \mathrm{N})$ ratio and analysis of variance (ANOVA) were employed to study the performance characteristics. They concluded that the feed rate and cutting speed were the most influential factors on the surface roughness and tool life, respectively.

\section{EXPERIMENTAL WORK}

\subsection{Work piece material}

Aluminium 2014 is taken for the study purpose. This alloy is known for its good machine ability, corrosion resistance and electrical conductivity. It shows considerable strength at subzero temperature and lose strength upon exposition to high temperature. It is being used in making of automobile and aircraft components. The composition of the alloy is shown in Table 1. Properties of aluminium 2014 alloy are shown in Table 2.

Table 1. Alloying elements of aluminium 2014

\begin{tabular}{|c|c|c|c|c|c|c|c|c|}
\hline $\mathbf{C u}$ & $\mathbf{S i}$ & $\mathbf{C r}$ & $\mathbf{T i}$ & $\mathbf{Z n}$ & $\mathbf{F e}$ & $\mathbf{M g}$ & $\mathbf{M n}$ & $\mathbf{A l}$ \\
\hline $3.9-5 \%$ & $0.5-1.2 \%$ & $0.1 \%$ & $0.15 \%$ & $0.2 \%$ & $0.7 \%$ & $0.2-0.8 \%$ & $0.4-1.2 \%$ & Balance \\
\hline
\end{tabular}

Table 2. Properties of aluminium 2014

\begin{tabular}{|l|c|c|c|c|c|}
\hline Density & Melting point & Elastic modulus & Poisson's ratio & Thermal expansion & Thermal conductivity \\
\hline $2.8 \mathrm{~g} / \mathrm{cm}^{3}$ & $510^{\circ} \mathrm{C}$ & $70-80 \mathrm{GPa}$ & 0.33 & $23\left(10^{-6} /{ }^{\circ} \mathrm{C}\right)$ & $192(\mathrm{~W} / \mathrm{mK})$ \\
\hline
\end{tabular}

\subsection{Methodology}

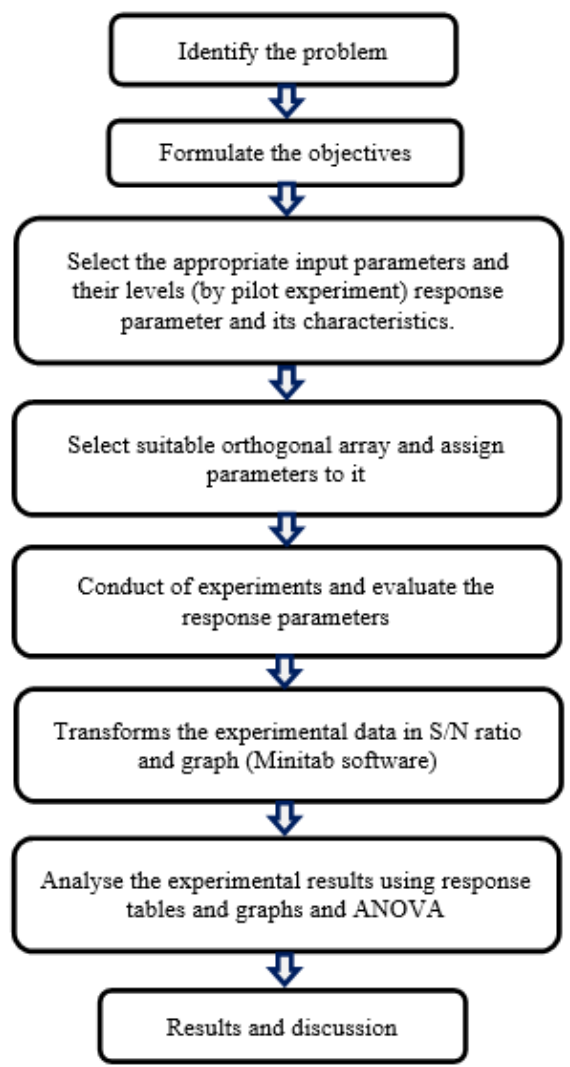

Figure 1. Methodology to perform optimization via Taguchi method and ANOVA

Design of experiments is a powerful tool for modelling and analysing the effect of control factors on response parameter [11]. Traditional experimental design becomes uneconomical and practically difficult when dealing with large number of machining parameters and experiments. Taguchi method of design of experiments comes handy in such situation as use of orthogonal array significantly reduces the number of experimental runs. Taguchi employed the signal-to-noise $(\mathrm{S} / \mathrm{N})$ ratio as the quality characteristic of choice [12-14]. $\mathrm{S} / \mathrm{N}$ ratio is used as a measurable value instead of standard deviation due to the fact that as the mean decreases, the standard deviation also decreases and vice versa.

The methodology adopted to conduct the study is shown in Figure 1 with the help of a flowchart. For this study, three turning process parameters namely cutting speed, depth of cut and feed rate were taken at three different levels, which are shown in Table 3.

Table 3. Process parameter with their levels

\begin{tabular}{|c|c|c|c|}
\hline Process Parameters & Level 1 & Level 2 & Level 3 \\
\hline Cutting speed $(\mathrm{rpm})$ & 1200 & 1500 & 1700 \\
\hline Depth of cut $(\mathrm{mm})$ & 0.2 & 0.4 & 0.6 \\
\hline Feed rate $(\mathrm{mm} / \mathrm{min})$ & 15 & 25 & 35 \\
\hline
\end{tabular}

\section{RESULTS AND DISCUSSIONS}

By using $\mathrm{L}_{9}$ orthogonal array, total nine experiments were designed as shown in Table 4. All the nine experiments were conducted on a CNC Machine on "MCL10" using HSS turning tool in dry condition. Surface roughness was measured and shown for each sample in Table 4 . S/N ratio and means obtained from the Minitab software have also been entered in Table 4. Figure 2(a) and (b) shows the main effects plot for Means and $\mathrm{S} / \mathrm{N}$ ratios, respectively.

In the figures, variation of response with various parameters is shown separately. In the figures, values of process parameters are shown on $\mathrm{x}$-axis and response values have been shown on y-axis. The horizontal line in the figures represents the mean of the response. It is evident from Figure 2(a) that $R_{a}$ is minimum at the middle level of depth of cut, third level of feed rate and third level of spindle speed.

In general, surface roughness value should be minimised, hence in this study we took smaller-the-better $\mathrm{S} / \mathrm{N}$ ratio. By evaluating the result through the $\mathrm{S} / \mathrm{N}$ ratio plot, we found that 
the optimum values of parameters i.e. depth of cut, feed rate and spindle speed are $0.4 \mathrm{~mm}, 35 \mathrm{~mm} / \mathrm{min}$ and $1700 \mathrm{rpm}$ respectively. Further, analysis of variance (ANOVA) is carried out to quantify the effect of turning parameters on the surface roughness $[15,16]$. Result of ANOVA is given in Table 5. It also determines the percentage contribution.
It can be seen that spindle speed is the most prominent parameter and has most effect on mean value of the $R_{a}$. Feed rate is the second prominent parameter and depth of cut is the least significant. The responses for means and $\mathrm{S} / \mathrm{N}$ ratios have been summarised in Table 6 and 7, respectively.

Table 4. $\mathrm{L}_{9}$ experiments with measured surface roughness, $\mathrm{S} / \mathrm{N}$ ratio and means

\begin{tabular}{|c|c|c|c|c|c|c|}
\hline Exp. No. & Depth of cut & Feed rate & Cuting Speed & Surface roughness $(\boldsymbol{\mu m})$ & S/N Ratio & Means \\
\hline 1 & 0.2 & 15 & 1200 & 1.41400 & -3.0089 & 1.4140 \\
\hline 2 & 0.2 & 25 & 1500 & 0.88427 & 1.0680 & 0.8843 \\
\hline 3 & 0.2 & 35 & 1700 & 0.76111 & 2.3715 & 0.7611 \\
\hline 4 & 0.4 & 15 & 1500 & 1.04600 & -0.3906 & 1.0460 \\
\hline 5 & 0.4 & 25 & 1700 & 0.74900 & 2.5106 & 0.7490 \\
\hline 6 & 0.4 & 35 & 1200 & 1.04300 & -0.3656 & 1.0430 \\
\hline 7 & 0.6 & 15 & 1700 & 0.97300 & 0.2377 & 0.9730 \\
\hline 8 & 0.6 & 25 & 1200 & 1.24400 & -1.8964 & 1.2440 \\
\hline 9 & 0.6 & 35 & 1500 & 0.75400 & 2.4525 & 0.7540 \\
\hline
\end{tabular}

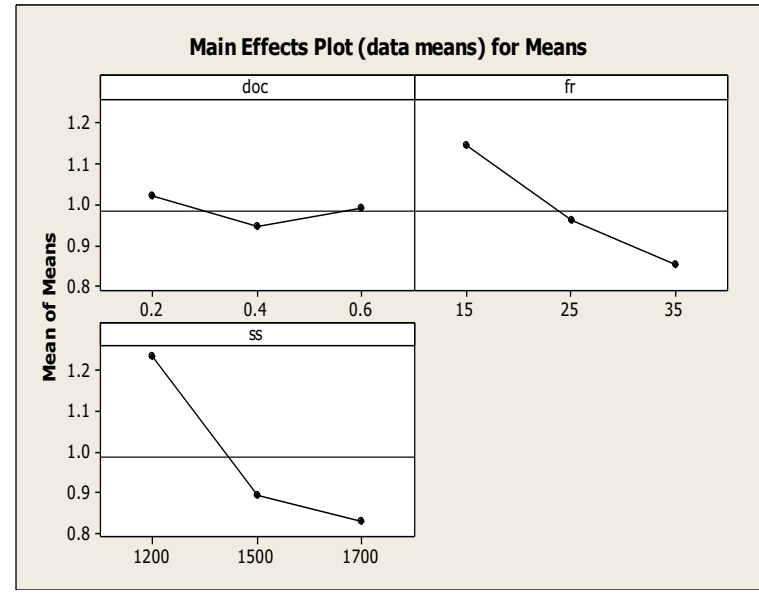

(a)

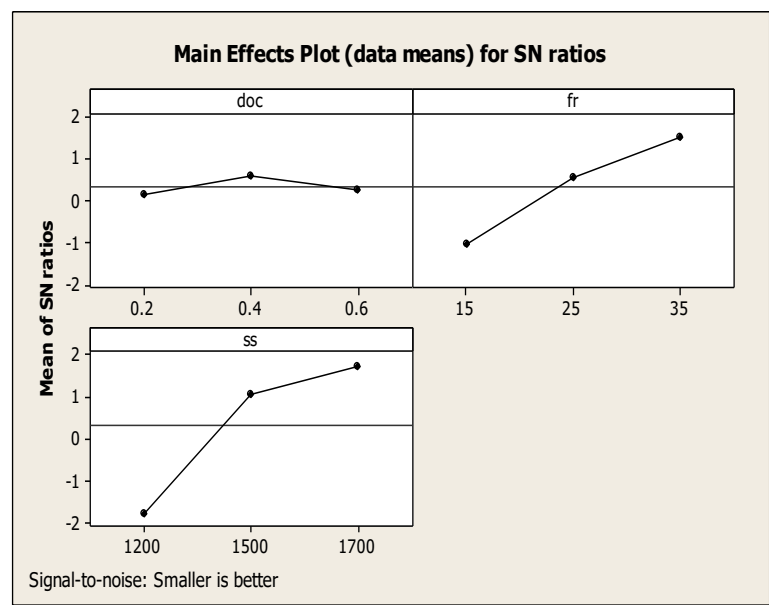

(b)

Figure 2. (a) Main effect plot for means; (b) Main effect plot for $\mathrm{S} / \mathrm{N}$ ratios

Table 5. Analysis of variance (ANOVA) for surface roughness

\begin{tabular}{|c|c|c|c|c|c|c|c|}
\hline Source & DF & Seq SS & Adj SS & Adj MS & F & P & \% Contribution \\
\hline Depth of cut & 1 & 0.0013 & 0.0013 & 0.0013 & 0.20 & 0.674 & 0.33 \\
\hline Feed rate & 1 & 0.1275 & 0.1275 & 0.1275 & 19.58 & 0.007 & 32.29 \\
\hline Spindle speed & 1 & 0.2662 & 0.2662 & 0.2662 & 40.86 & 0.001 & 67.38 \\
\hline Residual error & 5 & 0.0325 & 0.0325 & 0.0065 & - & - & - \\
\hline Total & 8 & 0.4277 & - & - & - & - & - \\
\hline
\end{tabular}

Estimated Model Coefficients $\mathrm{S}=0.0807229, \mathrm{R}-\mathrm{Sq}=92.38 \%$ and $\mathrm{R}-\mathrm{Sq}(\operatorname{adj})=87.81 \%$.

Table 6. Response table for means

\begin{tabular}{|c|c|c|c|}
\hline Levels & Depth of cut & Feed rate & Spindle speed \\
\hline 1 & 1.0198 & 1.1443 & 1.2337 \\
\hline 2 & 0.9460 & 0.9591 & 0.8948 \\
\hline 3 & 0.9903 & 0.8527 & 0.8277 \\
\hline Delta & 0.0738 & 0.2916 & 0.4060 \\
\hline Rank & 3 & 2 & 1 \\
\hline
\end{tabular}

Table 7. Response table for $\mathrm{S} / \mathrm{N}$ ratios

\begin{tabular}{|c|c|c|c|}
\hline Levels & Depth of cut & Feed rate & Spindle speed \\
\hline 1 & 0.1435 & -1.0540 & -1.7570 \\
\hline 2 & 0.5847 & 0.5608 & 1.0434 \\
\hline 3 & 0.2646 & 1.4860 & 1.7064 \\
\hline Delta & 0.4412 & 2.5399 & 3.4634 \\
\hline Rank & 3 & 2 & 1 \\
\hline
\end{tabular}

\section{CONCLUSIONS}

The present work depicts an experimental way to show the effect of CNC cutting parameters on surface roughness of aluminum 2014 alloy.

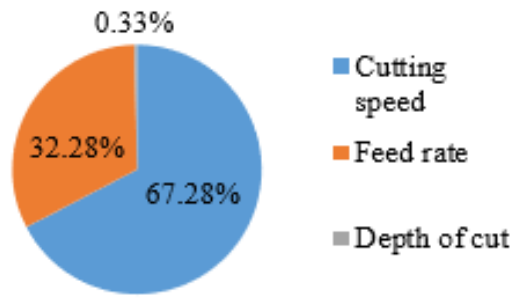

Figure 3. Percent-wise significance of cutting parameters on surface roughness 
It has been found that Taguchi's robust design approach is quite suitable to tackle surface roughness (metal cutting) problem as discussed in the paper. The optimum combination of turning parameters to achieve minimum surface roughness is $1700 \mathrm{rpm}, 0.4 \mathrm{~mm}$ and $35 \mathrm{~mm} / \mathrm{min}$. Cutting speed has maximum effect followed by feed rate and depth of cut on surface roughness. Figure 3 depicts the significance of the parameters in percentage.

\section{REFERENCES}

[1] Masounave, J., Youssef, A., Yves, B., Marc, T. (1997). An experimental design for surface roughness and builtup edge formation in lathe dry turning. International Journal of Quality Science, 2(3): 167-180. https://doi.org/10.1108/13598539710170803

[2] Ghani, J.A., Choudhury, I.A., Hassan, H.H. (2004). Application of Taguchi method in the optimization of end milling parameters. Journal of Materials Processing Technology, 145(1): 84-92. https://doi.org/10.1016/S0924-0136(03)00865-3

[3] Gopalsamy, B.M., Mondal, B., Ghosh, S. (2009). Taguchi method and ANOVA: An approach for process parameters optimization of hard machining while machining hardened steel. Journal of Scientific and Industrial Research, 68: 686-695. http://nopr.niscair.res.in/handle/123456789/5301

[4] Sarýkaya, M., Dilipak, H., Gezgin, A. (2015). Optimization of the process parameters for surface roughness and tool life in face milling using the Taguchi analysis. Materials Technology, 49(1): 139-147.

[5] Surace, R., De Filippis, L.A.C., Ludovico, A.D., Boghetich, G. (2010). Application of Taguchi method for the multi-objective optimization of aluminium foam manufacturing parameters. International Journal of $\begin{array}{lll}\text { Material } & \text { Forming, } & 3(1):\end{array}$ http://dx.doi.org/10.1007/s12289-009-0409-9

[6] Dahbi, S., Moussami, E.H., Ezzine, L. (2015). Optimization of turning parameters for surface Roughness for turning process of Steel AISI 1042 (58.55 HRC). Xème Conférence Internationale: Conception et Production Intégrées, Tanger, Morocco.

[7] Yang, W.P., Tarng, Y.S. (1998). Design optimization of cutting parameters for turning operations based on the Taguchi method. Journal of Materials Processing Technology,
122-9.
http://dx.doi.org/10.1016/S0924-0136(98)00079-X

[8] Pang, J.S., Ansari, M.N.M., Zaroog, O.S., Ali, M.H., Sapuan, S.M. (2014). Taguchi design optimization of machining parameters on the CNC end milling process of halloysite nanotube with aluminium reinforced epoxy matrix (HNT/Al/Ep) hybrid composite. HBRC Journal 10(2):

$138-144$ http://dx.doi.org/10.1016/j.hbrcj.2013.09.007

[9] Nalbant, M., Gökkaya, H., Sur, G. (2007). Application of Taguchi method in the optimization of cutting parameters for surface roughness in turning. Materials \& Design, 28(4): 1379-1385. http://dx.doi.org/10.1016/j.matdes.2006.01.008

[10] Hasçalık, A., Çaydaş, U. (2008). Optimization of turning parameters for surface roughness and tool life based on the Taguchi method. The International Journal of Advanced Manufacturing Technology, 38(9-10): 896-903. https://doi.org/10.1007/s00170-007-1147-0

[11] Benardos, P.G., Vosniakos, G.C. (2002). Prediction of surface roughness in CNC face milling using neural networks and Taguchi's design of experiments. Robotics and Computer-Integrated Manufacturing, 18(5-6): 343354. https://doi.org/10.1016/S0736-5845(02)00005-4

[12] Park, S.H., Kim, J. (1996). Quality engineering using robust design and analysis. Springer Nature, Berlin. https://doi.org/10.1007/978-3-642-59268-3_1

[13] Mahapatra, S.S., Patnaik, A. (2007). Optimization of wire electrical discharge machining (WEDM) process parameters using Taguchi method. The International Journal of Advanced Manufacturing Technology, 34(910): 911-925. https://doi.org/10.1007/s00170-006-06726

[14] Vijian, P., Arunachalam, V.P. (2006). Optimization of squeeze cast parameters of LM6 aluminium alloy for surface roughness using Taguchi method. Journal of Materials Processing Technology, 180(1-3): 161-166. https://doi.org/10.1016/j.jmatprotec.2006.05.016

[15] Cicek, A., Kıvak, T., Samtaş, G. (2012). Application of Taguchi method for surface roughness and roundness error in drilling of AISI 316 stainless steel. Strojniški Vestnik-Journal of Mechanical Engineering, 58(3): 165174. https://doi.org/10.5545/sv-jme.2011.167

[16] Kim, S.J., Kim, K.S., Jang, H. (2003). Optimization of manufacturing parameters for a brake lining using Taguchi method. Journal of Materials Processing Technology, 136(1-3): 202-208. https://doi.org/10.1016/S0924-0136(03)00159-6 